\title{
Hardware and software architecture for overhead line rating monitoring
}

\author{
I. Albizu, E. Fernández, A. J. Mazón, Member, IEEE, J. Bengoechea, and E. Torres
}

\begin{abstract}
Real time monitoring in both electrical transmission and distribution lines is an interesting option for knowing the electrical load level of these lines. The information about the load level allows alleviating the overloaded lines if the power can be transferred to other lines. In this paper, a new ampacity monitoring system for overhead lines, based on the conductor tension, the ambient temperature, the solar radiation and the current intensity, is presented. The measurements are transmitted via GPRS to a control center where a software program calculates the ampacity value. The system takes into account the creep deformation experienced by the conductors during their lifetime and calibrates the tension-temperature reference and the maximum allowable temperature in order to obtain the ampacity.
\end{abstract}

Index Terms-Ampacity, Overhead lines, Rating, Real time monitoring

\section{INTRODUCTION}

$\mathrm{T}$ HE power transmitted in both transmission and distribution electrical lines has increased considerably over the past twenty years. As a result of the increased power flow, some lines can be close to their ampacity limit. The ampacity or thermal rating is that current which will meet the design, security and safety criteria of a particular line. The conductor temperature depends on the current value and weather magnitudes. An increase in the conductor temperature produces an elongation of the conductor. This elongation can be dangerous for the reduction of the distance between the conductor and the ground or other lines that cross under them. So, it is important to maintain the flow of the lines below its ampacity limit.

One option to improve the power system could be the installation of new lines. However, the high population density, the intensive use of land and the increasing rejection of new electrical installations determine that a small amount of space is available to be dedicated to electrical lines. Therefore, there is great pressure to increase the power flow in existing right of ways using existing infrastructure as far as

This work is financially supported by the Bizkaiko Foru Aldundia and the UPV/EHU under the project DIPE08/22, the Ministerio de Ciencia e Innovación under the project DPI2009-08454, the Eusko Jaurlaritzako Hezkuntza, Unibertsitate eta Ikerketa Saila (Euskal unibertsitate-sistemako ikerketa-taldeak Ref. IT532-10) and the UPV/EHUren Ikerketako Errektoreordetza (Ikertzaileen prestakuntzarako laguntza)..

The authors are with the Electrical Engineering Department, Faculty of Engineeringof Bilbao, University of the Basque Country, Bilbao 48013, Spain (e-mail: igor.albizu@ehu.es; ;vira.fernandezh@ehu.es; javier.mazon@ehu.es; janbengares@hotmail.com; esther.torresi@ehu.es). possible. For this reason, methods without the need to strengthen the towers that allow increasing line power flow securely and safely, close to its ampacity limit, have been developed. Among these methods, real time monitoring can be found.

In this paper, a new ampacity monitoring system for overhead lines is presented. The system includes both hardware implementation and remote control software.

\section{REAL TIME MONITORING SYSTEMS}

The aim of the monitoring is not just the determination of the line state but the calculation of the actual ampacity or rating value. In other words, the monitoring is not limited to verify that the sag or the conductor temperature is below the limit value. It calculates the current intensity that makes the sag or the conductor temperature taking the limit value. Hence, one way to increase the power rating of the line is by monitoring a set of characteristic variables of the system. Real time monitoring systems will be described attending to the magnitude being monitored.

\section{A. Weather monitoring}

Real time rating by weather monitoring is the simplest system. It is also the least invasive system as the monitoring system does not need to be physically installed in the line. Hence, making use of weather stations in substations, weather monitoring is easy to apply.

Making a thermal calculation [1-2], the conductor temperature can be derived. The ampacity is calculated as the current intensity value that equals the conductor temperature to the temperature limit value. Some practical application cases are shown in [3-4]. The main drawback is that the conditions, especially the wind, can change along the line due to land irregularities, forests, etc. Hence, there is some uncertainty in the results that can be important in some cases.

\section{B. Conductor temperature monitoring}

Conductor temperature is monitored by a sensor installed in the conductor that measures its surface temperature. Hence, a direct temperature measurement is carried out.

However, the conductor temperature can change along the line due to the change of weather conditions. So, this technique reduces the uncertainty in determining the conductor temperature, but it does not remove it

Moreover, to calculate the ampacity, the weather condition values have to be known [5-6]. 


\section{Measurement of parameters: sag or tension}

As there is a direct relation between the tension and the sag values, the tension monitoring is a good indicator of the line condition when the sag is the magnitude to be controlled. The sag is obtained from the tension value, the span length and the weight per length unit of the conductor. Whereas the conductor temperature measurement is a local measurement, the tension represents the average condition of all the spans between two tension towers. This reduces the uncertainty of the measurement.

The tension is monitored by a load cell that is installed in series with the insulator strings. The load cell is located between the tower and the insulator string so that it is electrically insulated from the conductor [7-8].

The weather magnitude values are needed in order to calculate the ampacity value.

\section{GENERAL DESCRIPTION OF THE MONITORING SYSTEM}

In this paper a new ampacity monitoring system is presented. This monitoring system is based on an ampacity characterization methodology that considers only the monitoring of the mechanical tension, the ambient temperature, the solar radiation and the current intensity.

The main benefits of the system over other monitoring systems are the creep evaluation, the developed method for the calculation of the conductor temperature in the calibration and the simplicity of the required measuring elements.

The system evaluates and monitors the evolution of the creep. The only system that evaluates the creep is the Power Donut [9]. However, they are different systems because the system is based on tension monitoring while the Power Donut is based on temperature monitoring.

The system can calculate the conductor temperature with a low error. It is based on the detection of operation conditions with low wind and low current intensity. This method calculates the conductor temperature without the need of a direct conductor measuring system.

The system comprises four measuring elements: tension, ambient temperature, solar radiation and current intensity. There is no need for either wind speed or conductor temperature measurement. The measuring elements of the system have the advantage that they are installed at ground voltage. Other systems require the installation of elements at line voltage. This is the case of the monitoring systems based on the temperature measuring. The measuring elements of the system are general purpose elements that are found easily in the market. Other systems have elements that must be especially designed for the monitoring of the ampacity.

The system, which includes both hardware implementation and remote control software, allows knowing the maximum current intensity value that can take the monitored line according to the weather conditions.

\section{A. Hardware description}

The monitoring system developed needs to have some elements in the overhead line and in the control center (Fig 1).
These elements allow knowing the values needed for the calculation of the ampacity.

- A load cell allows monitoring the value of mechanical tension of the electrical conductor.

- A temperature sensor to measure the temperature.

- A radiation sensor that allows monitoring the solar radiation.

- A current intensity converter that allows monitoring the current intensity of one phase of the overhead line.

- Dataloggers that are used for acquiring the data from the sensors and transmitting the data, via GPRS, to the control center.

- A power supply system is needed to provide appropriate power supply for the operation of the sensors and the dataloggers. This system consists of a photovoltaic panel, a regulator and a battery.

Furthermore, as the values measured by the sensors are transmitted via GPRS to a control center, a PC with software for data management and ampacity calculation is required. This software includes the necessary formulation for evaluating the maximum allowable current, from the data measured in the field.
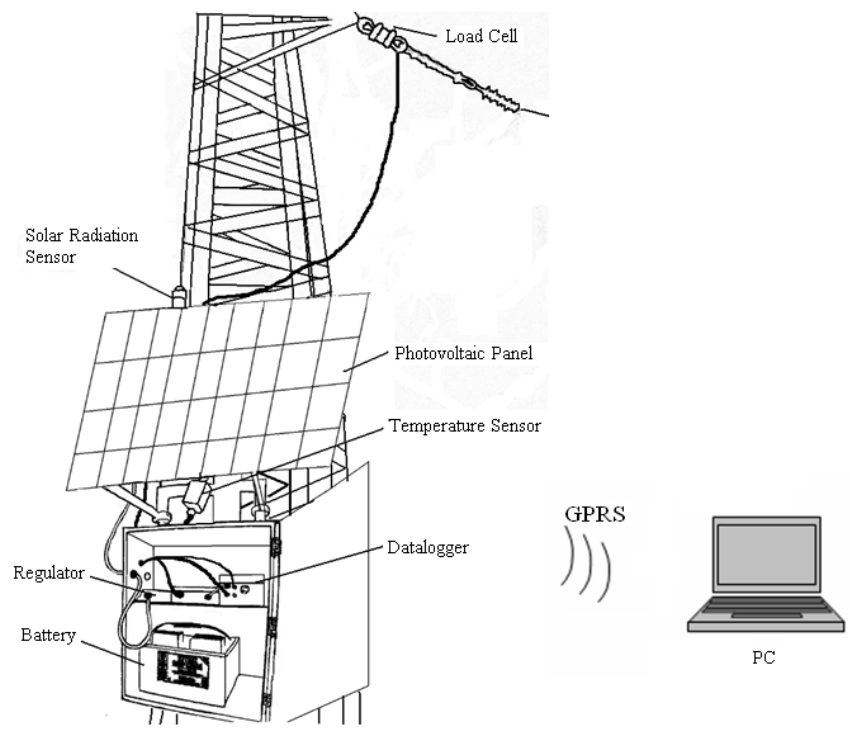

$\mathrm{PC}$

Fig. 1. Ampacity monitoring system

\section{B. Software description}

The developed software has been called TAM System (Tension \& Ampacity Monitoring System). This software processes the measurements of the sensors, carries out the necessary calculations and obtains the results of the ampacity of the monitored line. In addition, the system calculates the conductor temperature, the sag and takes into account the creep deformation experienced by the conductors during their lifetime.

The software program comprises a set of modules that carry out different tasks. 
1. Module of communication and management of the remote measurement systems.

This module manages the dataloggers. It also makes the statistical processing of the data in order to obtain reliable results in the monitoring.

Thus, the number of the datalogger SIM card can be defined. The port number where the modem for the communication with the dataloggers is connected can be also defined. The data download period can be defined and the period of time for the data processing too.

Besides, this module configures the analogue input channels of the dataloggers defining the relation between the measured signal and the magnitude measured by the sensor.

\section{Power line characterization module}

This module defines the parameter values that characterize the power line. Thus, the length of the span, the maximum sag, the type of conductor, the tension of the installation, etc. are defined. This module has a database of conductors where the user can add new types of conductors (Fig 3). In this database, the conductor parameters required for the calculation such as its area, elastic module, thermal expansion coefficient, weight, etc. are defined.

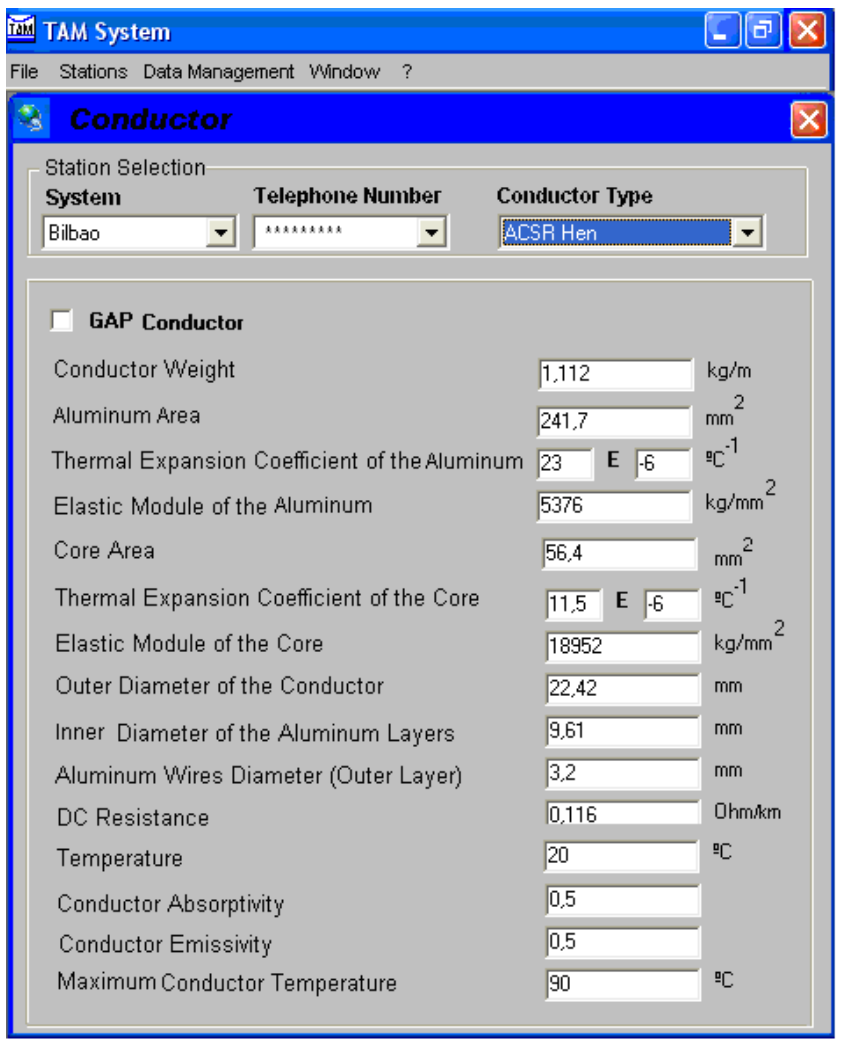

Fig. 3. Power line characterization module

\section{Processing and calculation module}

The developed system carries out two calculation processes that run in parallel: the tension-temperature calibration process and the process of ampacity calculation (Fig 4). Each of the processes is executed whenever new data is downloaded.

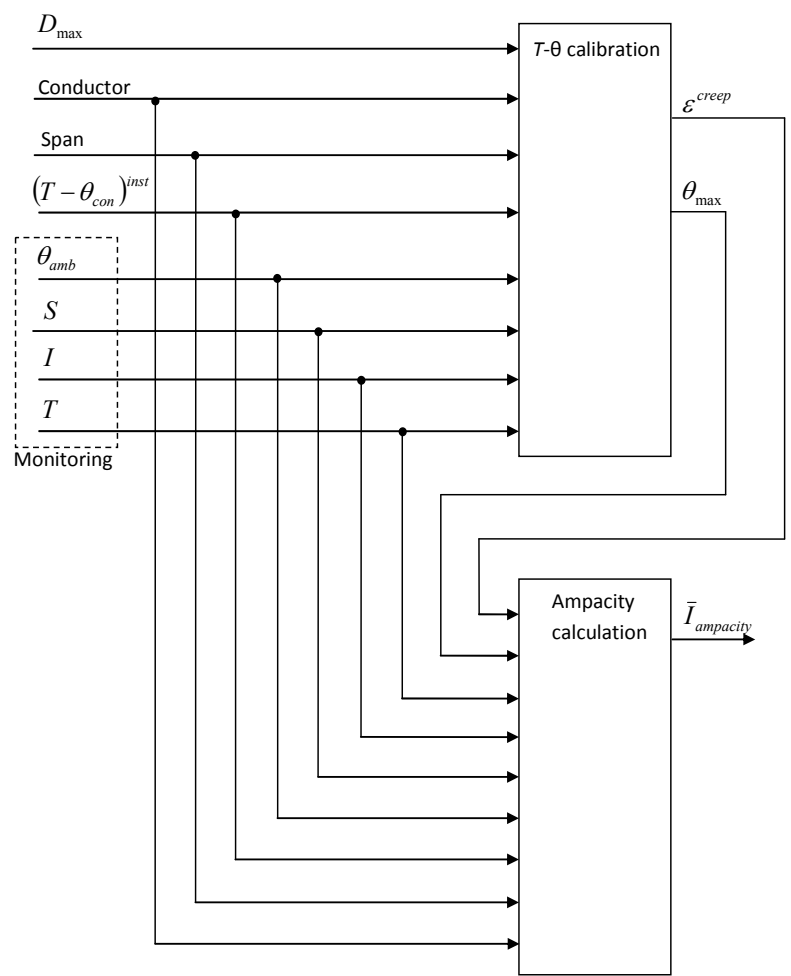

Fig. 4. Calculation module

\section{a) Process of ampacity calculation}

The process of ampacity calculation obtains continuously the ampacity value from the tension, $T$, the ambient temperature, $\theta_{a m b}$, the solar radiation, $S$, and the current intensity values, $I$.

In addition to the measurements taken by the sensors, other parameters are required for the ampacity calculation such as the conductor area, its elastic module, thermal expansion coefficient, the length of the span, the maximum sag, $D_{\max }$, etc.

It is also necessary to have the value of creep deformation, $\varepsilon^{\text {creep }}$, associated with the tension-temperature reference and the maximum allowable temperature, $\theta_{\max }$, related to the sag limit, $D_{\max }$. These values are provided by the calibration process.

The process of ampacity calculation is carried out continuously and the ampacity value is updated each time new measurements are taken.

The measurements are downloaded with a period of $t_{\text {download }}$. The number $k$ of downloaded data depends on the sampling period $t_{\text {sampling }}(1)$.

$t_{\text {download }}=k \cdot t_{\text {sampling }}$

To smooth the obtained ampacity curve, the mean values of the measurements during a period of time $t_{\text {mean }}$ are calculated. The number $m$ of measurements taken for the mean 
calculation is a function of the sampling period $t_{\text {sampling }}(2)$.

$$
t_{\text {mean }}=m \cdot t_{\text {sampling }}
$$

Thus, each time data is downloaded, the mean values of the tension $\bar{T}$, the ambient temperature $\bar{\theta}_{a m b}$, the solar radiation $\bar{S}$ and the current intensity $\bar{I}$ are calculated and the ampacity $\bar{I}_{\text {ampacity }}$ is calculated from those values. The equation (3) shows the calculation of the mean tension $\bar{T}_{j}$ as a function of the $m$ measured $T_{i}$ values. The calculation of the ambient temperature $\bar{\theta}_{a m b}$, the solar radiation $\bar{S}$ and the current intensity $\bar{I}$ is carried out in a similar way. Figures 5 and 6 show the results obtained from the measured values. In this example $t_{\text {sampling }}$ is one minute, $k=5$ and $m=20$.

$\bar{T}_{j}=\frac{\sum_{i=j-(m-1)}^{j} T_{i}}{m}$

Tension measurements (instantaneous)

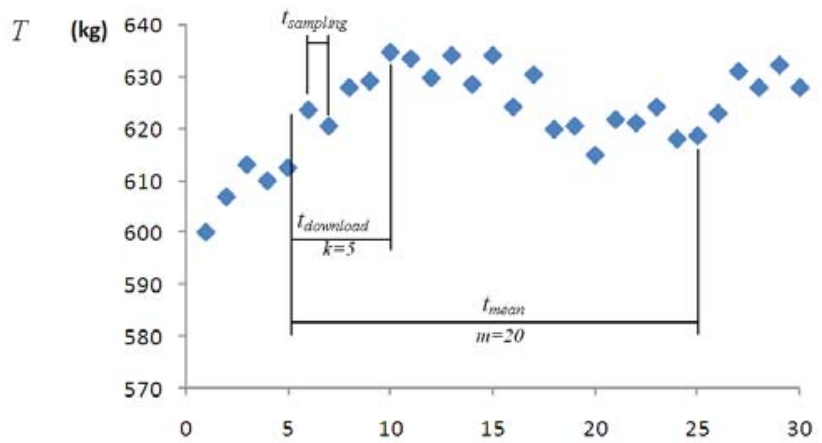

Fig. 5. Tension measurements: sampling, download and mean periods

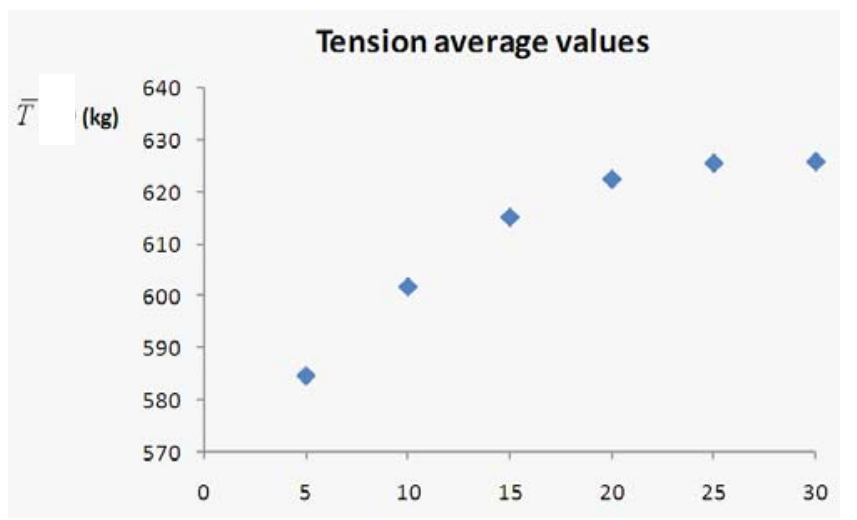

Fig. 6. Tension average values

For the calculation of the ampacity $\bar{I}_{\text {ampacity }}$, the first step is the calculation of the conductor temperature $\bar{\theta}_{c o n}$ from the tension $\bar{T}$. This is carried out by a sag-tension calculation model [10,11], which models the core and aluminum behavior independently including the creep. Then, the wind speed $\bar{v}$ is obtained. Finally, the ampacity $\bar{I}_{\text {ampacity }}$ is obtained from the conductor maximum allowable temperature $\theta_{\max }$, the ambient temperature $\bar{\theta}_{a m b}$, the solar radiation $\bar{S}$ and the calculated wind speed $\bar{v}$, using thermal balance equations where the unkown magnitude is the current intensity value that corresponds to the ampacity value.

\section{b) Tension-temperature calibration process}

The calibration establishes the relation between the conductor tension in a certain instant of time and the conductor temperature. The tension is measured directly. However, the conductor temperature value has to be estimated. The estimate of the conductor temperature is obtained from the tension, the ambient temperature, the solar radiation and the current intensity. Once the calibration is carried out, the creep strain and the maximum allowable temperature values are updated.

To assure a correct estimate of the conductor temperature, this is obtained from measurement mean values during a period of time $t_{\text {calibration. To guarantee that the temperature and }}$ tension values do not vary significantly during the period of tim, the tension standard deviation $\sigma_{T}$ is calculated and the period is valid if its value is below a threshold value $\sigma_{\text {Tthreshold }}$. The number $n$ of measurements taken for the mean and the deviation calculation is a function of the sampling period $t_{\text {sampling. }}$.

$$
\begin{aligned}
& t_{\text {calibration }}=n \cdot t_{\text {sampling }} \\
& \bar{T}_{j}=\frac{\sum_{i=j-(n-1)}^{j} T_{i}}{n} \\
& \sigma_{T, j}=\sqrt{\frac{\sum_{i=j-(n-1)}^{j}\left(T_{i}-\bar{T}_{j}\right)^{2}}{(n-1)}}
\end{aligned}
$$

Figure 7 shows an example where $n$ is 15. Figure 8 shows the results obtained for the tension standard deviation. The obtained values are above the deviation threshold, in this case $3 \mathrm{~kg}$, and as a consequence no calibration should be carried out. 
Tension measurements (instantaneous)

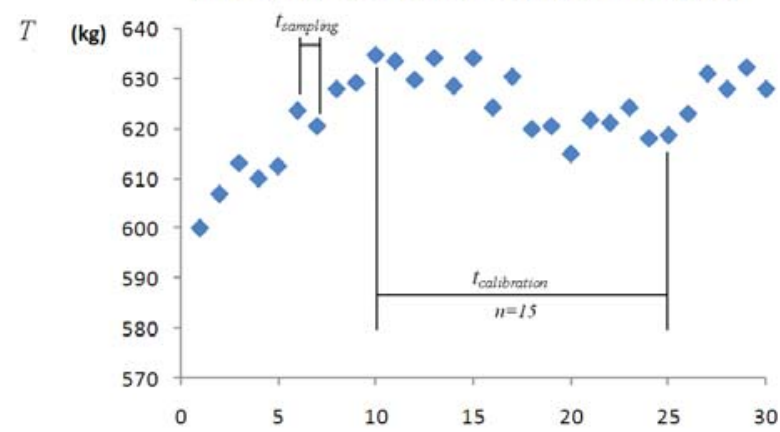

Fig. 7. Tension measurements: sampling and calibration period

\section{Tension deviation}

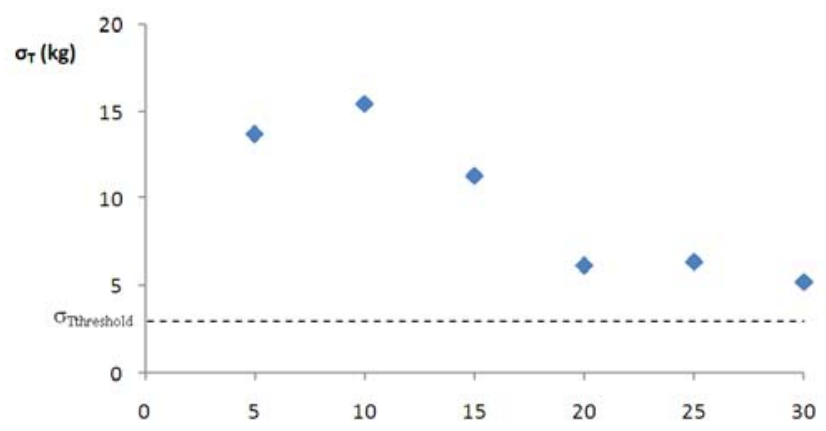

Fig. 8. Tension deviation

If the tension deviation is below the threshold value, a second condition is checked. The mean value of the current intensity $\bar{I}$ should be below a threshold value $\bar{I}_{\text {Threshold }}$.

When both conditions are met the conductor temperature is calculated. The conductor temperature $\bar{\theta}_{c o n}$ is calculated from the measured ambient temperature $\bar{\theta}_{a m b}$, solar radiation $\bar{S}$ and current intensity $\bar{I}$ using thermal balance equations. For this calculation a wind speed value is assumed.

The estimated conductor temperature $\bar{\theta}_{c o n}$ and the measured tension $\bar{T}$ result in the tension-temperature reference $T-\theta_{\text {con. }}$. Comparing this reference with the installation reference $\left(T-\theta_{c o n}\right)^{\text {inst }}$, the creep strain $\varepsilon^{\text {creep }}$ and the conductor maximum allowable temperature $\theta_{\max }$ related to the sag limit $D_{\max }$ are obtained by mechanical calculation.

\section{c) Ampacity uncertainty}

The uncertainty of the calculated ampacity values is a function of the uncertainty of the variables from which it is calculated. Thus, it is a function of the uncertainty of the measurement of the current intensity $\bar{I}$, the ambient temperature $\bar{\theta}_{a m b}$, the solar radiation $\bar{S}$ and the mechanical tension $\bar{T}$ and the estimate of the conductor temperature $\bar{\theta}_{c o n}$ and the wind $\bar{v}$. The analysis carried out has shown that the variables that most affect the ampacity uncertainty are the temperatures [12]. An error in the temperature difference between the conductor temperature and the ambient temperature results in an error of the wind value. The error in the wind speed is translated into an error in the ampacity. When the difference between the conductor temperature and the ambient temperature is low the influence of the temperature error in the ampacity calculation is higher and vice versa. When the current intensity increases, the temperature difference increases and as a consequence, the ampacity error decreases.

\section{Results module}

Using this module it is possible to monitor the evolution of the ampacity calculated (Fig 9). Similarly, the measured and calculated variables are recorded in a database that can be viewed retrospectively in order to discuss different incidents.

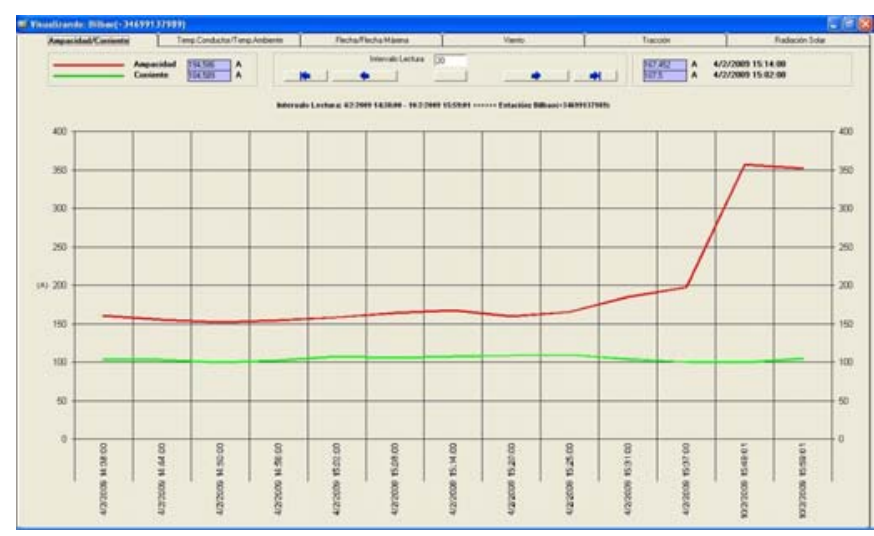

Fig. 9. Results module

\section{CONCLUSIONS}

In this paper, a new ampacity monitoring system for overhead lines is presented. This system, which includes both a hardware implementation and remote control software, allows determining the ampacity of the line.

The system has been developed seeking simplicity (low cost), reliability and accuracy in the calculated ampacity value. The main benefits of the system over other monitoring systems are the creep evaluation, the developed method for the calculation of the conductor temperature in the calibration and the simplicity of the required measuring elements.

The hardware system is formed by measuring elements and dataloggers that are used from acquiring and transmitting the data.

The software system comprises a set of modules that carry out different tasks: the module of communication and management of the remote measurement systems, the power line characterization module, the processing and calculation module and the results module.

The system will be tested in actual overhead lines and the results will be used to validate or adjust the defined threshold limits and improve the system. 


\section{REFERENCES}

[1] "Thermal behaviour of overhead conductors", CIGRÉ 22-12 Brochure (Ref. No. 207), 2002.

[2] IEEE Std 738-2006, "IEEE Standard for Calculating the CurrentTemperature Relationship of Bare Overhead Conductors", 2006.

[3] F. Soto, D. Alvira, L. Martín, J. Latorre, J. Lumbreras, M. Wagensberg, "Increasing the capacity of overhead lines in the $400 \mathrm{kV}$ Spanish transmission network: real time thermal ratings", CIGRÉ Session, 22211, Paris-France, 1998.

[4] H.J. Dräger, D. Hussels, R. Puffer, "Development and implementation of a monitoring-system to increase the capacity of overhead lines", CIGRÉ Session, B2-101, Paris-France, 2008.

[5] M.W. Davis, "A new thermal rating approach: The real time thermal rating system for strategic overhead transmission lines, Part I, General description and justification of the real time thermal rating system", IEEE Transactions on Power Apparatus and Systems, Vol. 96, No. 3, pp. 803-09, 1977

[6] S.D. Foss, S.H. Lin, R.A. Fernandes, "Dynamic thermal line ratings. Part I. Dynamic ampacity rating algorithm", IEEE Transactions on Power Apparatus and Systems, Vol. 102, No. 6, pp. 1858-64, 1983.

[7] T.O. Seppa, H.W. Adams, D.A. Douglass, N. Coad, A. Edris, P. Olivier F.R. Thrash, "Use of on-line tension monitoring for real-time thermal ratings, ice loads and other environmental effects", CIGRÉ Session, 22102, Paris-France, 1998.

[8] T.O. Seppa, "Increasing transmission capacity by real time monitoring", IEEE PES Winter Meeting, pp. 1208-11, 2002.

[9] J. Engelhardt, "Dynamic lyne rating system with real time tracking of conductor creep to establish the maximum allowable conductor loading as limited by clearance", US Patent 2007/0200556.

[10] I. Albizu, A.J. Mazon, I. Zamora, "Flexible strain-tension calculation method for gap-type overhead conductors", IEEE Transactions on Power Delivery, Vol. 24, No. 3, pp. 1529-1537, 2009.

[11] I. Albizu, A.J. Mazon, V. Valverde, G. Buigues, "Aspects to take into account in the application of mechanical calculation to high temperature low sag conductors", IET Generation Transmission \& Distribution, Vol. 4, No. 5, pp. 631-640, 2010.

[12] I. Albizu, E. Fernandez, A.J. Mazon, J. Bengoechea, "Influence of the conductor temperature error on the overhead line ampacity monitoring systems", IET Generation Transmission \& Distribution, Vol. 5, 2011. 